\title{
Qualitative Study on Urban Morphology and Social Problems in Multi-Story Housing Projects
}

\author{
Ajman City as a Case Study
}

\author{
Emad S. Mushtaha ${ }^{1 *}$ \\ 1 Department of Architectural Engineering, College of Engineering, University of Sharjah \\ *Corresponding Author, Email: emushtaha@sharjah.ac.ae
}

Key words: Vandalism, Urban Forms, Social Housing, Arabian Gulf Region

\begin{abstract}
Urban development in the Arabian Gulf region has been remarkable within a relatively brief period. The urban expansion of Arabian Gulf cities includes many multi-story housing projects of urban form is influenced by those built in Europe during the post-World War II period of reconstruction. According to the literature, these types of urban forms in Europe are associated with a number of social problems concerning the health of some residents, antisocial behavior by youth and some types of crime. The aim of this research is to investigate the presence of social problems in the Gulf housing projects that embrace urban forms similar to those built in Europe. The study shows that some social problems such as vandalism are present in some projects. Thus, further research is recommended to determine the extent of existing problems and provide guidelines for new development.
\end{abstract}

\section{INTRODUCTION}

World War II caused significant destruction throughout Europe and forced the authorities in those countries to provide housing for Europe's many displaced families. The housing units were required within a very short timeframe and at the lowest cost. The German air strikes destroyed approximately 500,000 housing units in Britain alone, in addition to the hundreds of thousands of housing units that fell into disrepair during the economic recession before the war and during the war period. Most of those housing units were home to middle-income groups who were not able to find alternative housing.

Responsible parties came up with modern movement architecture for housing, specifically ideas for high-rise housing designed in new urban styles that did not follow traditional urban architectural styles. This was a quick and economic solution to the housing crisis (Figure 1). In addition, the high-rise designs limited the horizontal expansion of cities, which would typically encroach on precious agricultural land. Multi-story housing was ideal at that time as it decreased the plot sizes and maximized the housing units, generating maximum economic benefit because the plot size is directly related to the cost of each unit. This enabled the provision of shelter for 
those families that had lost their homes during the war. This phase witnessed the construction of thousands of multi-story housing units in Europe.

High hopes were set for multi-story housing during that period, and the social problems now associated with low- to middle-income groups living in such units did not arise until the late 1960s. Britain had thousands of multistory housing units ranging between six and thirty stories as well as thousands of other low-rise buildings, which were funded by central or local governments (Bullock, 2002).

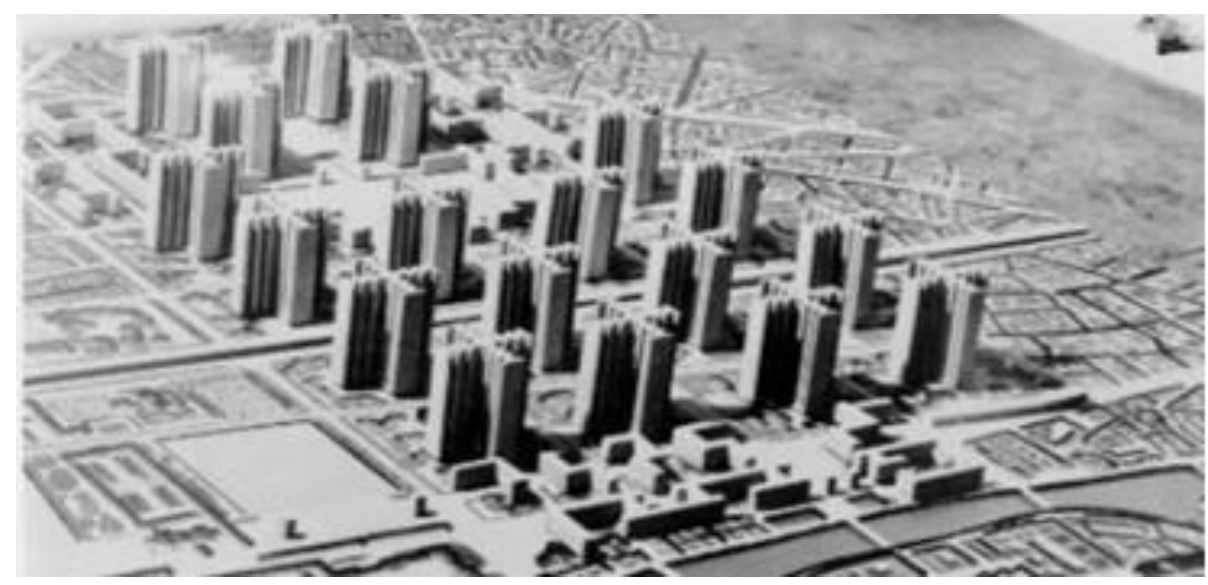

Figure 1. Le Corbusier proposal for building residential towers in Paris city center (1920)

It is clear that most of the new projects in the Gulf region are based on the urban architectural movement of residential high-rise buildings, which are in most cases surrounded by car parking and undesignated green areas. The buildings are disconnected from each other and have similarities to the urban (non-traditional) forms of the mega projects in Britain and other European countries after World War II. To demonstrate the main types of urban (non-traditional) forms and their characteristics, urban traditional forms and their characteristics must be identified to understand the difference between the two.

\section{TYPES AND CHARACTERISTICS OF URBAN TRADITIONAL FORMS OF MULTI-STORY RESIDENTIAL BUILDINGS IN BRITAIN}

Traditional urban forms have proved their success and flexibility to adapt to meet the changing requirements of urban life. The urban forms discussed here are not those that date back to historic ages but those that spread dramatically throughout European cities and the world. Those urban forms consist of streets surrounding blocks, where each block is divided into plots on which one or more buildings are erected along the side of the road. The plots are usually fenced or have clear distinctive boundary markings. In Britain, for instance, the traditional urban forms built during the British Empire's reign in the 19th century are still in use and have been adapted to suit the needs of the particular period. Furthermore, in response to social problems that are related to non-traditional urban forms (as will be shown later), there are many British and American narratives that are in favor of a return to and the development of traditional urban forms because they have been proven successful and have positive social characteristics (Bentley, 
1985; Calthorpe, 1993). This research classifies the traditional urban multistory housing forms in Britain and surroundings into three main types (Figure 2).

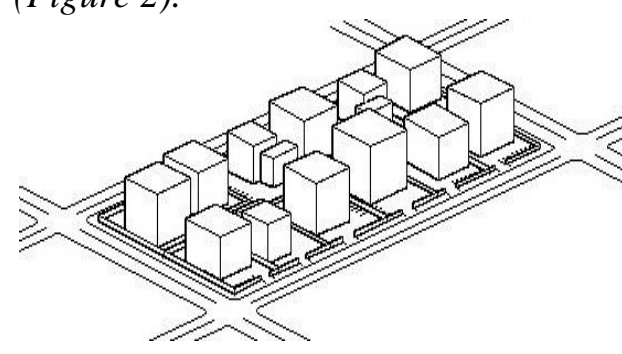

1. Fenced plot urban form
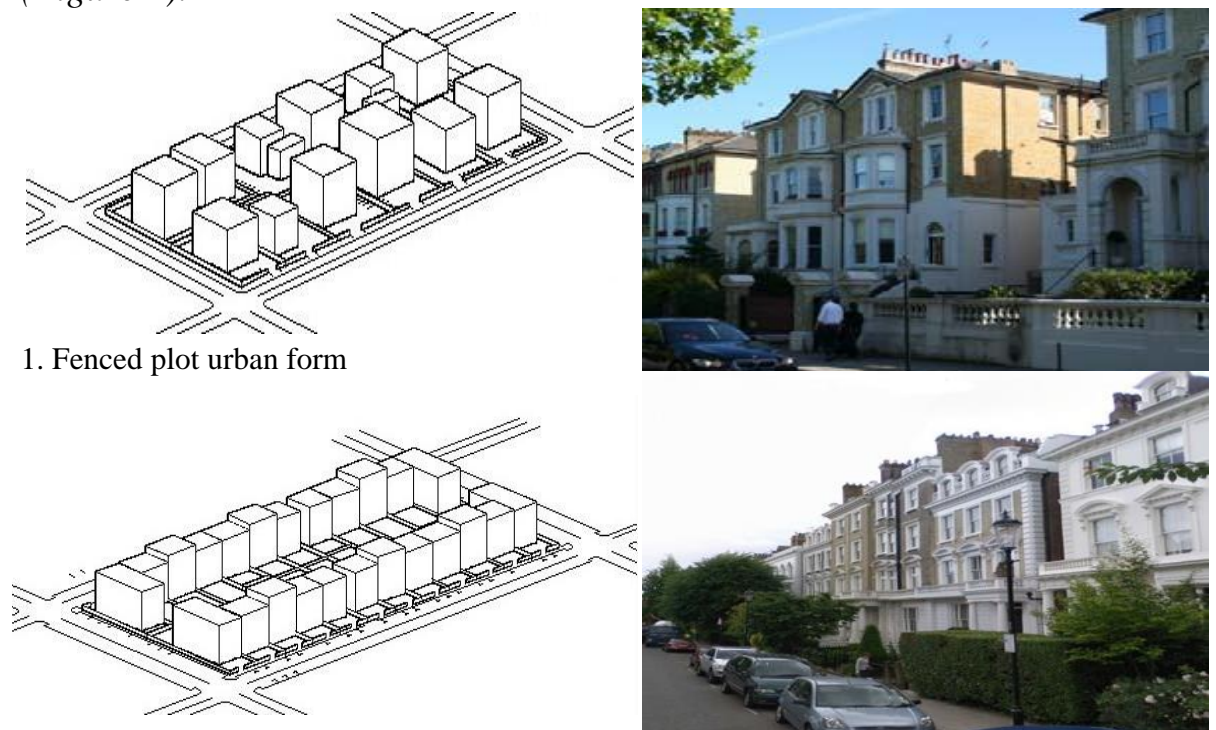

2. Conjoined urban form

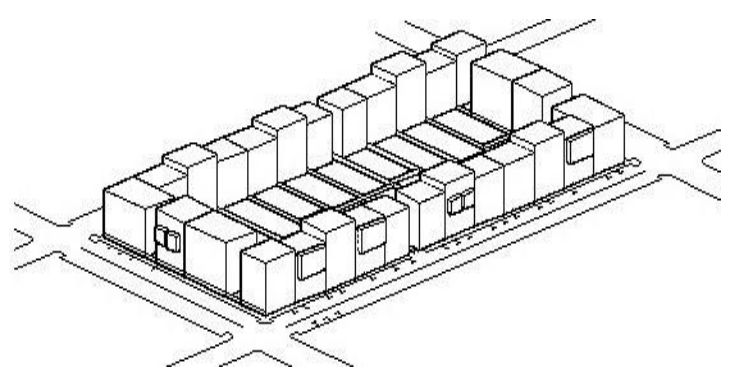

3. Conjoined multiuse urban form

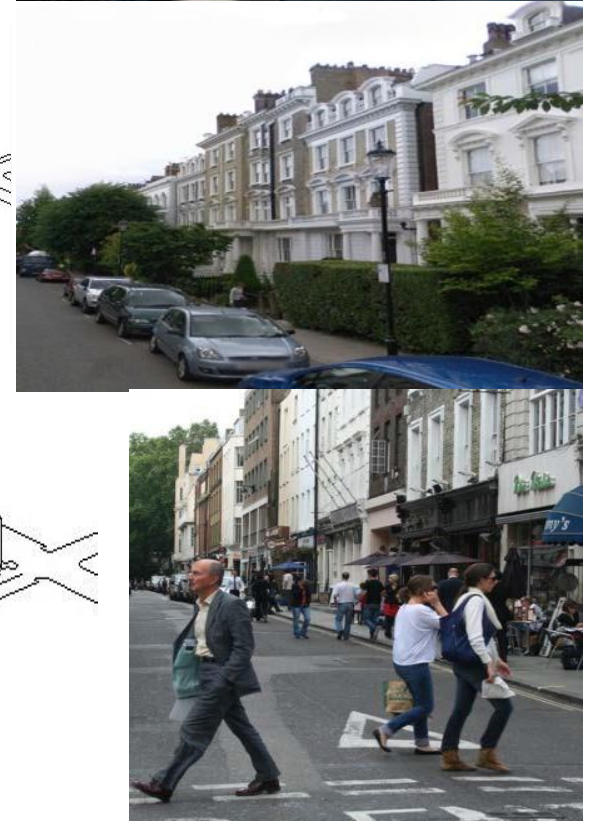

Figure 2. Models and examples of urban traditional forms of multi-story residential buildings in Britain

\subsection{Fenced Plots Urban Form}

Streets surround the blocks in the district and each block is divided into plots that are positioned along the length of the street. Each plot has a new building or an existing building that has been expanded or renovated as a multi-story residential building. Each building is surrounded by a green area or a paved sidewalk, and each plot is usually fenced or has clear defined boundaries.

\subsection{Conjoined or Semi-Conjoined Urban Form}

This form is similar to the fenced plots urban form but there are some differences in the houses and multi-story buildings: they are connected from one or two sides along the street and usually have a front and back yard. Those yards are usually clearly marked with fences or distinctive features. Buildings are typically close to the streets or have no front yard so that the building entrance is positioned directly on the street. The semi-conjoined buildings are two or three buildings connected together and separated from the next block of two or three buildings. 


\subsection{Conjoined Multi-Use Urban Form}

Similar to the above mentioned urban form but here the multi-story buildings are positioned along the street edges or the sidewalk, and each building will only have a backyard. The ground floor for each building will often be used as a commercial area, and the rest of the upper floors are residential.

Traditional city plots are mostly a mix of the urban forms mentioned above. Figure 2 shows examples of those traditional urban forms. From the above discussion, three commonly shared characteristics of the three traditional urban forms are identified:

1. Clear boundaries of private and public spaces and clear block boundaries where the streets surround the plots and buildings are positioned along the street length.

2. Human scale reference for building heights.

3. Variable and multi uses of buildings.

\section{TYPES AND CHARACTERISTICS OF URBAN NON-TRADITIONAL FORMS OF MULTI-STORY RESIDENTIAL BUILDINGS AFTER WORLD WAR II IN BRITAIN}

This research categorizes the main types of post-World War II urban non-traditional forms of British mega projects of multi-story residential buildings into two main categories. Figure 3 shows images of these two categories, which are as follows:

\subsection{Random Urban Form}

Residential areas are home to apartment buildings in the form of towers or mid-rise buildings (occasionally mixed with housing communities that are randomly spaced) and are surrounded by semi-public green or paved areas. Those areas include car parking and amenities such as garbage and electrical rooms. The apartment buildings might be placed along a road network, which appear at first glance to be similar to traditional urban forms but are in fact characterized by randomness.

\subsection{Urban Form with a Podium}

This urban form consists of a building that covers the whole project area in the form of a podium of one or more floors. The residential buildings are erected above the podium and can include towers or mid-rise buildings, and occasionally houses. The roof of the podium is used as an open space or a green area for residents in addition to amenities for the services provided on the roof. The podium can house car parking or housing units, and in some cases entertainment or commercial uses can be implemented either in the podium or on the roof in line with the buildings.

Some urban forms with a podium include several podiums under the residential buildings and connected to each other with bridges at different levels. This urban form is also characterized by several entrances and exits to the residential compounds. 


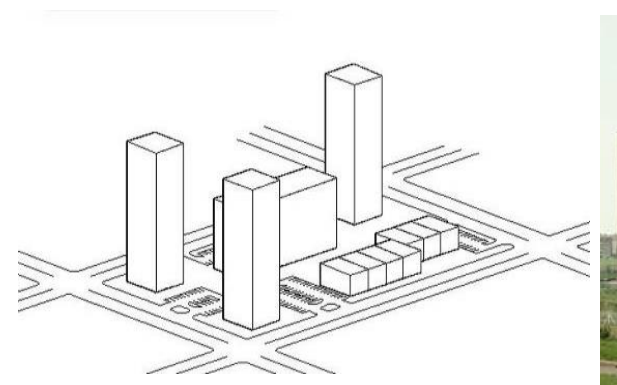

1. Random Urban Form

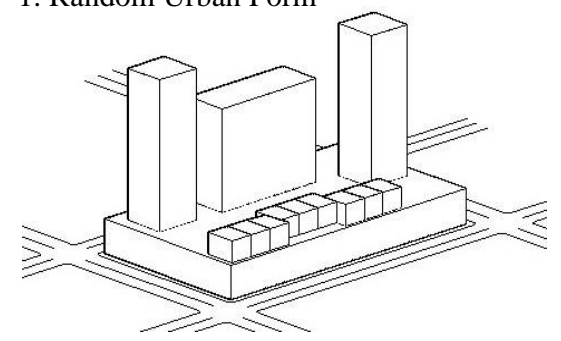

2. Urban Form with a Podium

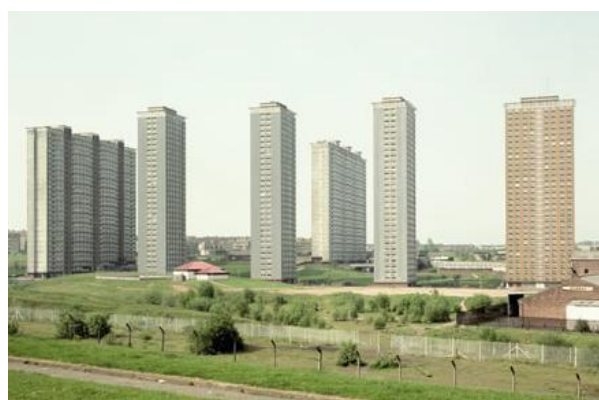

Figure 3. Models and examples for the urban non-traditional forms for multi-story residential buildings in Britain

Some projects consist of a mix of both of the forms mentioned above: conjoined housing compounds and distributed randomly between multi-story residential buildings. Figure 3 shows examples of the two types in British cities. Based on the outline above, three common characteristics distinguishing those two urban forms are as follows:

1. A Street and block network and undefined public spaces, where (in many cases) the buildings are surrounded by car parking and have undefined open public and private spaces around the buildings.

2. Increased building height and size and a lack of human scale found in traditional urban forms, with increased numbers of entrances and exits especially in large residential buildings connected with bridges or podiums.

3. Single use, where most of the buildings are specifically designed for residential purposes with a few limited services such as food stores, in contrast with traditional urban forms that are distinguished by the variety and proximity of residential, cultural, commercial and other uses.

\section{SOCIAL PROBLEMS RELATED TO PROJECTS AFTER WORLD WAR II IN BRITAIN AND ITS RELATION TO URBAN FORM}

This section specifically studies the narratives regarding the British experiment, and the social issues related to high-rise apartment housing. In Britain, once the buildings were inhabited, a large number of research and reports were published regarding the social and family problems in some social groups of the low- to middle-income inhabitants, including various health issues of children, mothers and older adults, as well as antisocial and violent behavior of teenagers. The multi-story buildings were also associated with a breakdown of social relations and an increase in crime among those social groups.

In the late 1970s and throughout the 1980s and 1990s, such residential projects in Europe and other Western countries posed a problem rather than 
a solution to the housing problem. In the 1980s and 1990s in Britain, those mid- and high-rise residential buildings built in between 1950 and the 1970s were demolished or rehabilitated. Rehabilitation is the process of changing the use of a building from its originally designed purpose. Each building is carefully studied to be transformed according to location and surrounding social issues.

Many high-rise buildings aged between 20 and 30 years have been demolished (Figure 4) and replaced with residential buildings derived from traditional urban forms.

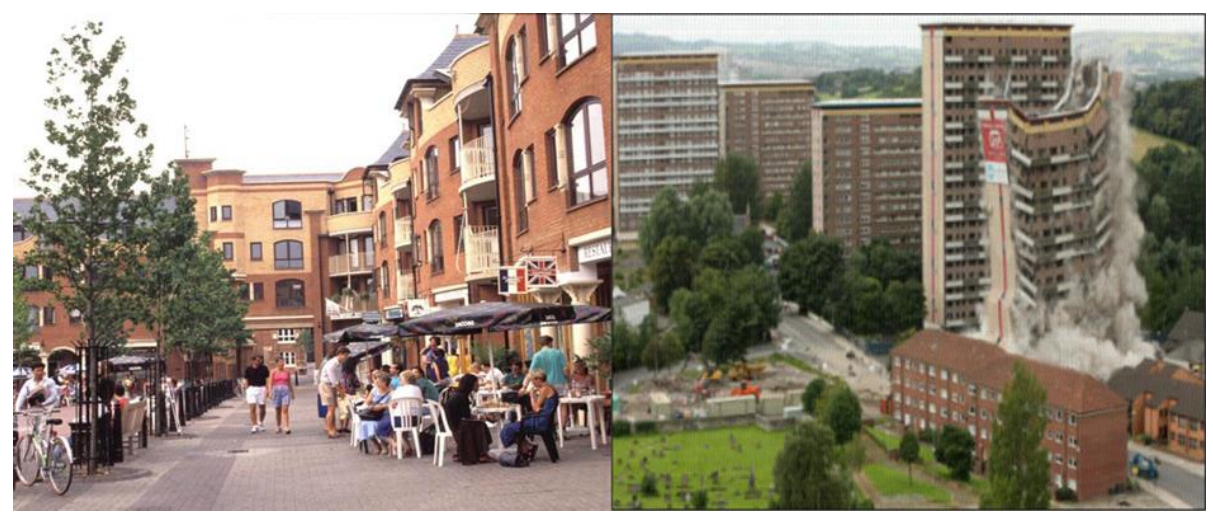

Figure 4. Example of British buildings demolished after 3-4 Decades (Right) and example of buildings that replaced them of traditional urban form design (Left)

Furthermore, residential towers in unique locations have been transformed to other uses such as office buildings or residential buildings for single people and students. Other buildings have been transformed to suit high-income earners willing to inhabit multi-story buildings near the city center or as a second home for those who also live outside the city. Duncan (1988) highlighted a number of rehabilitation projects for high-rise residential buildings to improve the public spaces around the buildings for the use of residents. Similarly, the higher floors of the buildings were demolished resulting in mid-rise residential buildings or houses. Previous studies show that three factors aggravated social problems related to residential projects after World War II in Britain:

1. Urban form.

2. Residents' social characteristics

3. Residential building management systems (Figure 5).

Although this research is concerned with the effect of the urban form on social life, other relevant factors also exist. Below is a revision of the key social problems related to residential projects constructed in Britain after World War II.

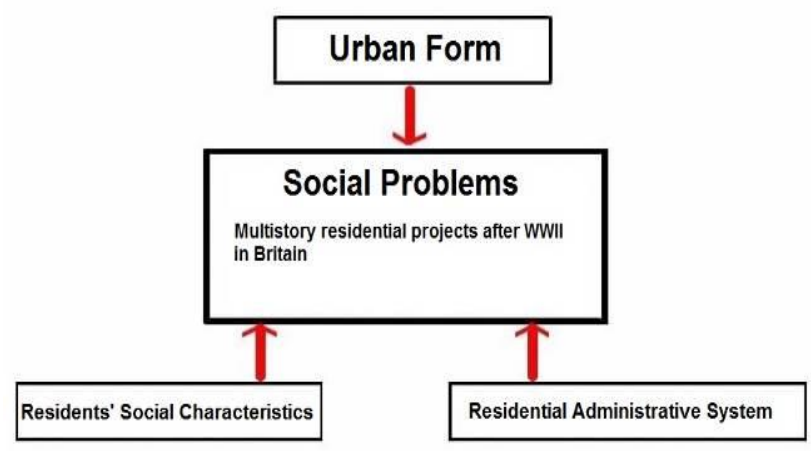


Figure 5. Factors influencing social problems in projects constructed after World War II in

Europe and their relation to urban form

\subsection{Antisocial Behavior of Children and Teenagers and Related Crime}

One of the most serious social problems related to high-rise residential buildings is antisocial behavior from teens and children (Figure 6) and crime. Since the expansion such buildings in Western countries after World War II, many official reports, journals and newspaper articles have been published regarding such issues and many theories for the causes have been proposed. Despite the many theories, they all point (either directly or indirectly) to the relation between social problems and the non-traditional urban form of residential building compounds. Such problems recur in open spaces that have no clear ownership and are away from the eyes of tenants such as open spaces surrounding the buildings, the rooftops of podiums, and car parking (Attenburrow, Murphy, \& Simon, 1978; Burbidge, 1981; Anderson, 2000; Faizi, Hosseini, \& Asl, 2008; Hillier \& Shu, 2000). Coleman (1985) produced a seminal work on the causes of such problems, Utopia on Trial, where she identified the relation between social problems and the size and height of residential high-rise buildings. Thus, these urban forms might create an anonymous environment when compared to traditional urban forms.

The theory claims that traditional urban forms consisting of streets surrounding the buildings and houses give the tenants a sense of belonging because of the clear boundaries of the plot and the surroundings they live in. In contrast, non-traditional high-rise buildings reduce the residents' sense of identity. For example, a tenant on a higher floor cannot relate to the surroundings of the building. In addition, this leads to children and teenagers engaging in antisocial behavior, expressing their dissatisfaction of their residential surroundings. Coleman was influenced by the writing of Newman $\underline{(1973)}$ in his American narrative of this theory, especially in his research presented in his book Defensible Space, where he discusses particular crimes in New York City residential components.

Coleman supported Newman's conclusions and included detailed statistics showing the increase in different social problems suffered by residents living in non-traditional urban form projects, particularly those characterized with height, large open areas around the buildings, podiums, connecting bridges, several entrances, and isolated car parking. These characteristics are considered as supporting factors for antisocial behavior and crime as they reduce the tenants' views of their surroundings and aid concealing strangers' access and movement.

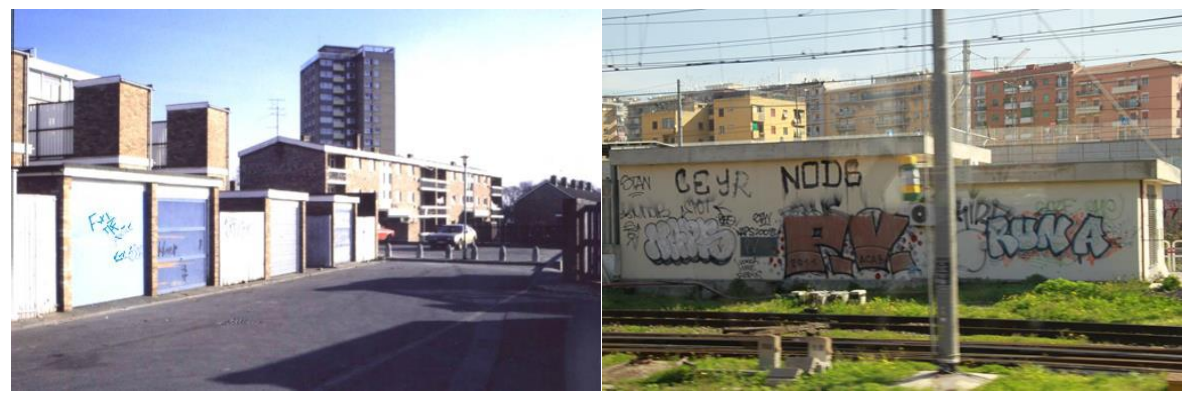


Figure 6. Images of antisocial behavior by teenagers on random urban form buildings in Oxford (left) and Rome (right)

Although those two studies present statistics confirming the increase in antisocial behavior and crime in the surroundings of high-rise apartment buildings and those designed using non-traditional urban forms, the theories do not explain the reason for the occurrence of similar antisocial behavior in traditional urban forms. Thus, there must exist a more holistic reason for the existence for such problems in both traditional and non-traditional urban forms but with different percentages. This concludes that there is the need for more in-depth and extensive research on that subject, to specifically identify those factors and present a more holistic theory.

\subsection{Increase of Diseases among the Population}

Studies on the relation between residential apartments and the increase in the incidence of disease among residents have identified the main reason for this problem: social isolation resulting from the nature of the project design and its effects on certain social groups such as housewives, children, older adults and especially low- to middle-income earners.

Research into this problem started after the spread of high-rise residential buildings in the 1960s (Bone, 1977; Mahdjoubi, 2007; Williams, 1991). A seminal study was that by a British professor Fanning (1967) who discovered an increase in respiratory system diseases, particularly in children living in residential apartments when compared with those living in houses. It has also been shown that tenants on higher levels suffer more psychological illness than tenants on lower floors (Fanning, 1967). To explain the rationale behind these findings, Fanning and other researchers have presented a theory that isolation resulting from height is the reason for such diseases. The theory suggests that high-level residence does not encourage housewives and older adults to communicate; instead, they use internal passages to enter and exit the building with no use of open public spaces, which are mostly filled with car parking.

Fanning (1967) results have been confirmed in other studies, with one of the most remarkable being that by Bone (1977), where it was found out that children living in houses spend much more time playing outside than those living in residential apartments. Further research has demonstrated other problems related to family life such as the decrease of social relations for mothers and resident children and their friends. The above studies are exclusive to low- and middle-income groups living in residential compounds. Other research shows that those problems are not applicable to high-income groups living in high-rise residential apartments when compared with houses. The reports indicate a positive effect of raised income level as their apartments are usually more spacious, in addition to the possibility of hiring home help and the use of other high-end facilities such as social clubs, and they can afford holidays. These benefits eliminate the loneliness felt by low- to middle-income groups (children, mothers and older adults).

Research by Mahdjoubi (2007) relates health problems to high-rise inhabitants, stating that apartment housing is related to diseases whose incidence has recently increased in Britain (e.g., diabetes in children). This is directly related to the apartment lifestyle where children spend less or no time outside the apartment and parents refrain from letting their children 
play in the areas surrounding the buildings because of the bad design of the open areas and unavailability of play areas.

\subsection{Vicious Circle (VC)}

The occurrence of any of social problems mentioned above is usually an indication of a more complicated problem, commonly referred to by scholars in urban studies as The Vicious Circle. In Britain, since the 1970s, a number of scholars have studied discussions of this problem in different media including daily newspapers and occupational magazines (Bullock, 2002; Godfery, 1977; Medway, 1973), confirming that this problem multiplies the social problems resulting in the extreme deterioration of the residential compound or the apartment building.

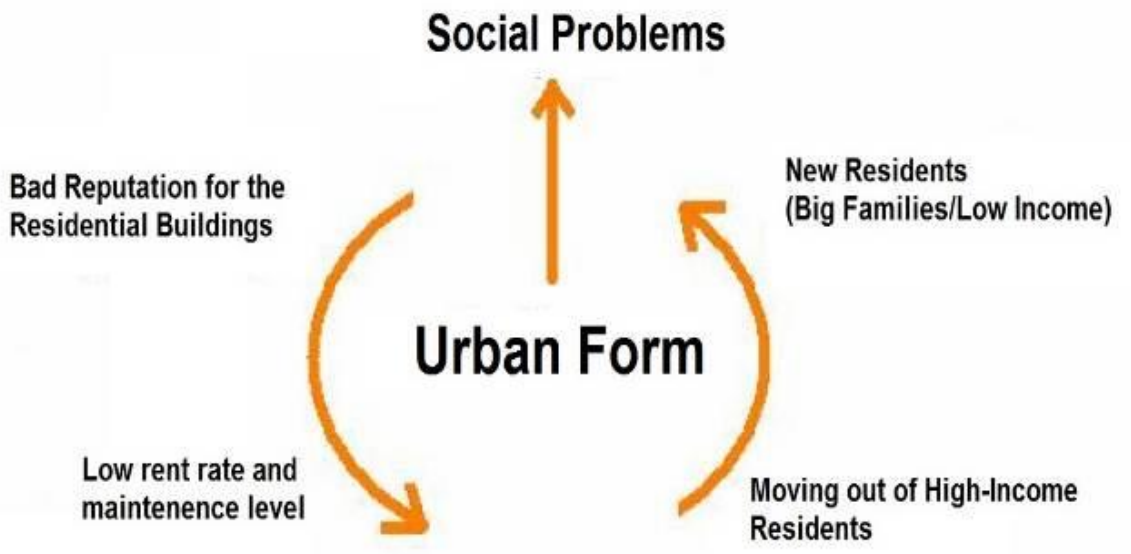

Figure 7. Evolution of the Vicious Circle problem

Figure 7 shows the evolution of the vicious circle problem. When problems start to arise in an apartment building or a residential compound, for any of the reasons mentioned beforehand, then this building or compound will gain bad reputation. In the British context, this building or compound will feature in local newspapers and media in relation to negative behavior or crime. This will worsen the reputation, which might also be accompanied with a deterioration of the image of the building due to vandalism or destruction to the façade.

As a result, people who have the chance to change their residence do so; these people are usually wealthier tenants. Other residents, who accept the condition as it is, are those who do not care about the reputation or the deterioration because of their need for a home. Therefore, the compound becomes a home for new immigrants, multi-family residents, large groups of single men or large families with limited income. This increases the problems and adds fuel to the fire. As a result, the rents are lowered, which forces the landlord to ignore building maintenance. This vicious circle continues until the building or compound becomes home for society's least fortunate and is turned into a hub of crime and poverty.

It is normal for such social groups to exist as part of society, but their concentration in a building or compound that suffers from improper design and social issues makes the problem grow. Thus, those parts of the city are transformed into isolated communities or "ghettos," affecting the areas and communities surrounding it. 
The vicious circle problem emerged many years after the buildings were first tenanted, with the constant change of tenants. This problem was encountered in the apartment buildings and residential compounds built in Europe after World War II. In Britain, many such compounds were demolished in the 1980s and 1990s. There are also such communities in Paris, inhabited by those at the bottom of the French social pyramid (e.g., new immigrants and the unemployed) and they pose a social security problem.

Researchers and authors have suggested many solutions to the vicious circle problem. Wilson (1977) studied the problem and identified the relation between improper design practices and the careless management of buildings and compounds, showing that poor maintenance and low rent acted to increase the issues and problems. Wilson suggests that the solution is proper management and consulting residents about managerial and rent issues. In addition, Ward (1983), among others, believes the optimum solution for the social problems leading to the vicious circle problem is to train residents to manage their own communities and buildings through social cooperative unions. The assumption presented is that residents will feel a sense of responsibility and this will force them to care for their neighborhood and surroundings, reducing destruction and strengthening social relations. The above studies indicate that most social problems in relation to high-rise housing are directly related to the design; this could change if the designer understood how his decisions and plans might affect the life of the residents. This confirms the importance of the design as a cause and solution to social problems. Although other factors can affect the situation, the design remains the main reason in these issues and problems.

\section{AN EXPLORATIVE STUDY ON THE SOCIAL PROBLEMS OF SIMILAR URBAN FORMS OF ARABIAN GULF AND BRITISH PROJECTS}

Cultural differences can have a significant impact on social problems. There is currently no research on the effect of high-rise housing and nontraditional urban forms in Gulf countries or the Middle East on issues related to the health of children, mothers and older adults or the antisocial behavior and crime of children and teenagers. However, there are some measures that can be easily recorded, providing evidence of various issues such as graffiti and the vandalism of public spaces by children and teenagers. Those problems seem to be recurrent in residential areas or residential projects constructed in Europe after World War II. This explorative study is a preliminary study that will concentrate on those two problems. The aim of this study is to form a basis for future studies on that subject.

There is little difficulty in concluding that most new projects in the Gulf area are designed according to the modern movement in architecture in the form of high-rise apartment buildings, in most cases surrounded by car parking areas, open green spaces and unspecified open green areas. These are similar to the non-traditional urban forms of projects in European cities, specifically random urban forms and urban forms with podiums.

The present study required on-site visits to many residential projects to document the previously discussed issues, photographing some of the features and interviewing the management of residential buildings. 


\subsection{Observation on Vandalism in Public Areas}

This problem was found to be common around a number of high-rise residential buildings and seems to be related to the urban form. In some random urban form projects a phenomenon was observed that residents seem not to notice many vandalized walls in public spaces and around uninhabited apartments on the ground floor (Figure 8). After interviewing some of the upper management, it is apparent that the increase in the percentage of children and teenage residents has resulted in the increase of this problem (Hamid, Arar, \& Mushtaha, 2011). Although projects designed in a podium urban form are new to the Gulf area, this study has observed examples of vandalism. In some projects with podiums, vandalism to the walls above the podium and in car parking areas were recorded, despite the relatively newness of the buildings (Figure 9).

\subsection{Observations of the Extent of the (VC)}

The research shows that some older high-rise residential apartments are caught in the vicious circle problem. Higher management confirmed that those areas have enjoyed a lower rent for some time and thus have undergone little maintenance (Figure 10). The research also shows that there are other reasons related to the urban form that might have negative effects, such as a scarcity of car parking, public spaces and children's playgrounds. This results in the empty spaces around the buildings being used as car parking areas. Often public spaces around the buildings are centralized with electrical generators and garbage collection rooms, which make them unsuitable for social communication and dangerous as playgrounds. The above reasons might force good tenants to leave the area looking for suburbs with higher standards of living. They are then replaced with new immigrants and poorer, large families causing the area to become a hub for social problems.

\subsection{Further Observation of Vandalism}

One housing area, Al Nuamiya district, in Ajman city was selected to investigate many factors related to problems of vandalism. The residential area was built and completed in 2006. The area consists of 15 residential blocks of flats in 17 floors. The housing district covers an area of 27,810 square meters, with 15,060 square meters of open public spaces (Figure 8).

The effect of the perceptions of visibility was assessed in terms of their impact on graffiti. After collecting the data from different locations in the site, 17 vandalized locations were observed. The graffiti size was measured directly from the site using a digital camera. Then, the measurements of the area covered by graffiti were grouped within six classes of visibility (Figure.11). As a result, the graffiti area decreased with an increase in the perception of visibility as in (Mushtaha \& Hamid, 2017). Therefore, this study shows the importance of having high degree of the perception of visibility through windows, which in turn reduces vandalism seen from dwellings.

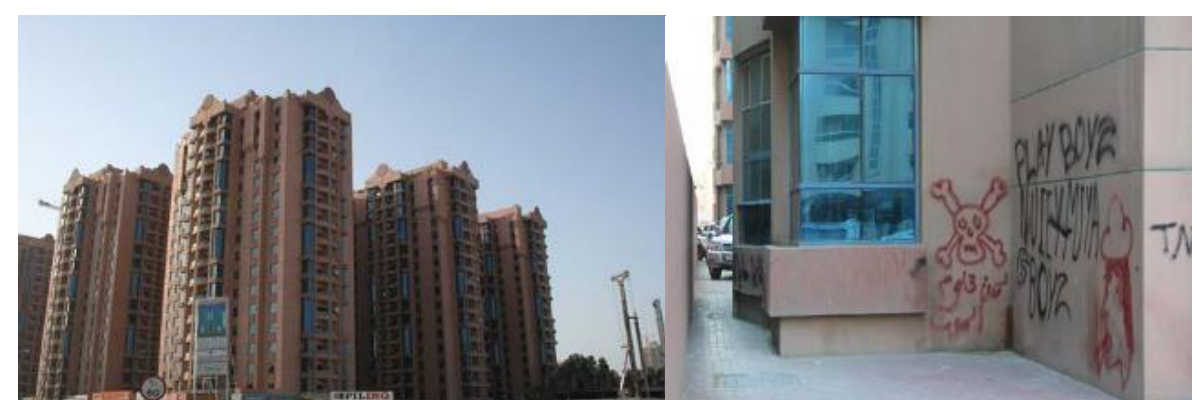


Figure 8. Random urban form project in the Arabian Gulf showing antisocial behavior from teenagers

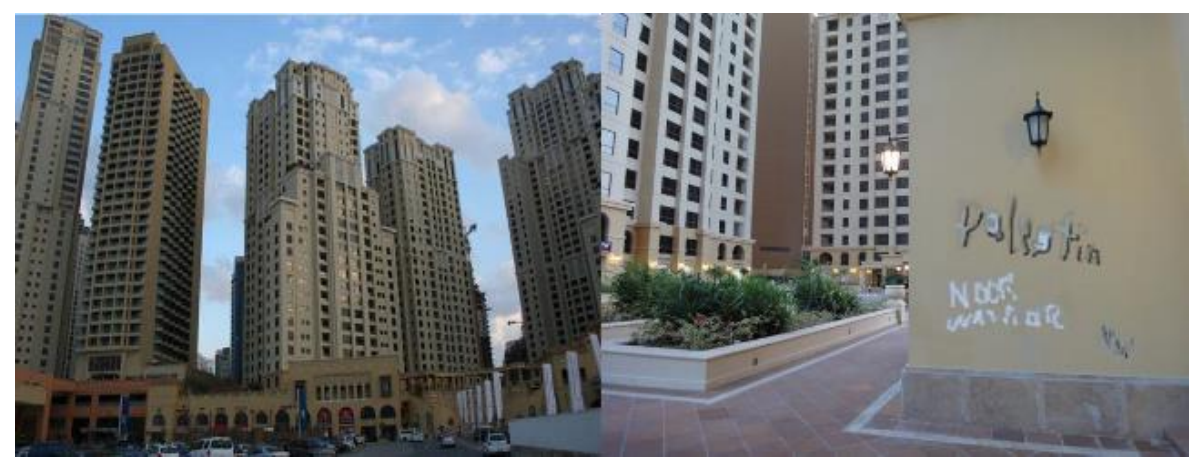

Figure 9. New Gulf project with podium showing vandalism by teenagers in areas obscured from view and car parking

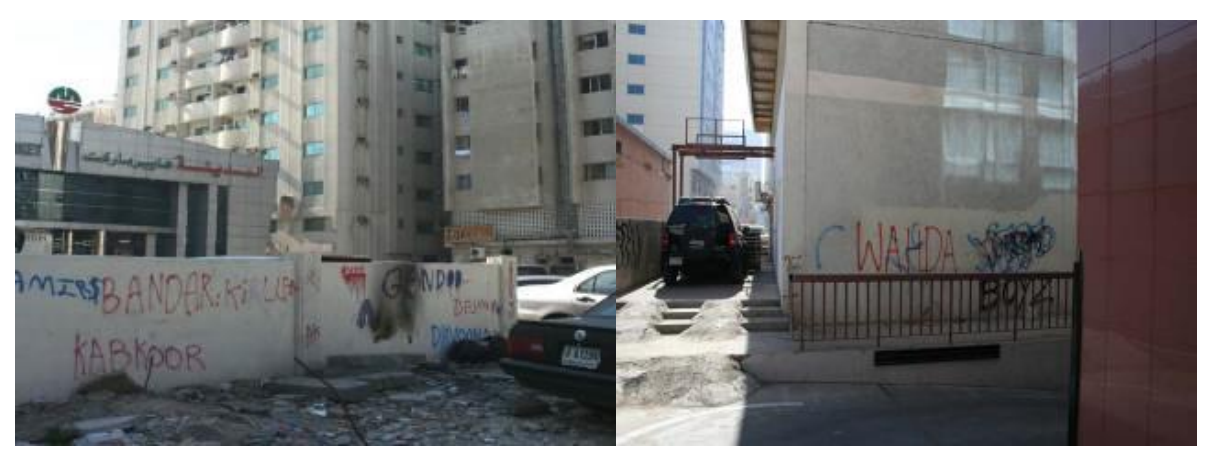

Figure 10. Relatively old high-rise residential apartment buildings where antisocial activity has led to the vicious circle problem

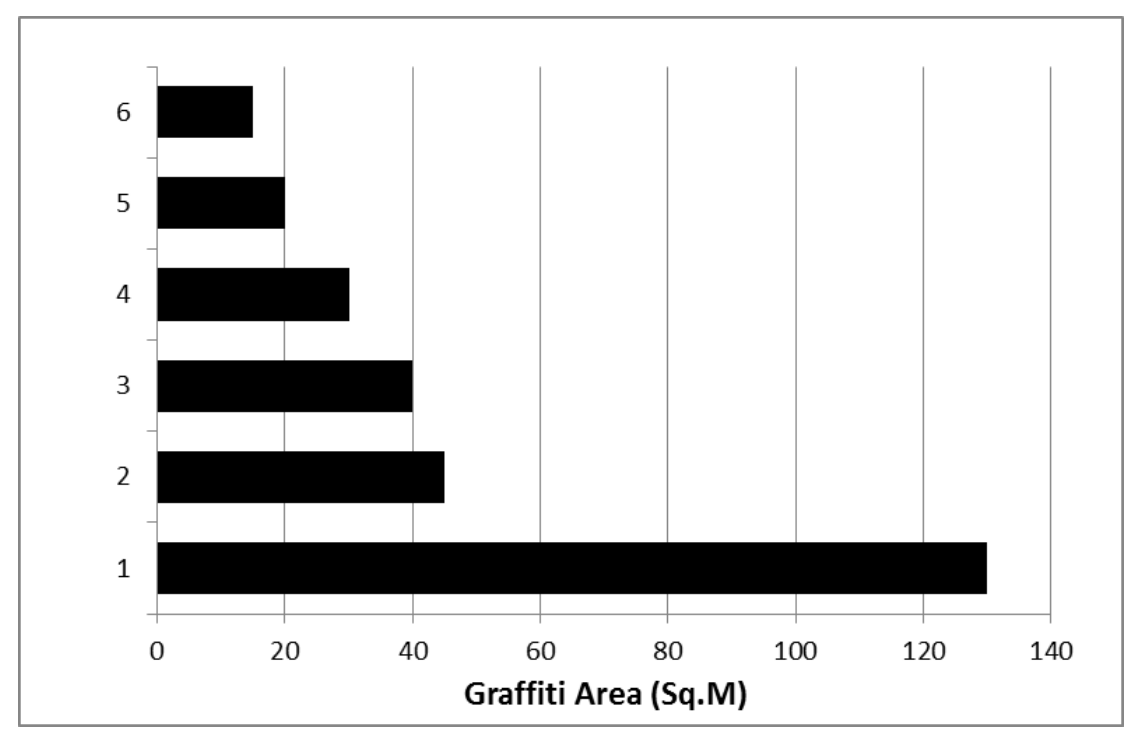


Figure 11. Perception of visibility and graffiti

\section{CONCLUSIONS}

The present research identifies a number of social problems in high-rise building in the Gulf regions, specifically vandalism to walls and public spaces by teenagers and children. The vicious circle problem is recurrent in Gulf residential projects, similar to that in European projects. Other problems, including the increase of diseases among children, mothers and older adults, and increased crime rates were not touched on in this preliminary study and require more resources to undergo an in-depth analysis. This study represents the first part of extensive research exploring the problem of vandalism and graffiti in the public spaces of high-rise residential areas in the Gulf region. The following study should investigate relevant methods and measurements to reduce vandalism in public spaces. However, based on the present study, it is necessary to perform further investigations into all aspects of these social problems to determine the causes and how pervasive are they in Gulf projects. These findings would be the basis for designing and planning residential projects. Lessons learned, which can be deduced from this research, show that high-rise buildings might be unsuitable for a high percentage of low- to middle-income families. Therefore, this housing option should only be available for high-income groups. High-rise residential buildings might be an option in city centers to provide high-income families and single people with this type of housing, should they prefer such housing. Furthermore, to avoid those problems typically resulting from the urban form of the projects, and based on the findings of this study, it is clear that such projects need to be redesigned and replanned to ensure that they are safe and controlled. This specifically requires defined public and private spaces around the buildings and to encourage residents to monitor any activities in these areas. It is also recommended that open spaces be assigned designated uses; that is, transformed into green areas to be enjoyed by lower-floor families and older adults.

The above lessons can be implemented in new projects where it seems that it is preferable to avoid non-traditional urban forms and return to the study of the traditional urban form. The latter has evolved throughout the ages and has the possibility to serve new needs without destroying its positive characteristics.

\section{ACKNOWLEDGMENT}

The author is very grateful to Dr. Faisal Hamid for his contribution to the study. His thorough discussion and immense support from the initial to the end helped the author present this work properly. 


\section{REFERENCES}

Anderson, I. (2000). "Housing and Social Exclusion: The Changing Debate". In Anderson, I. \& Sim, D. (Eds.), Social Exclusion and Housing: Context and Challenges, (pp. 6-21). Coventry: Chartered Institute of Housing.

Attenburrow, J., Murphy, A., \& Simon, A. (1978). "The Problems of Some Large Authority Estates, an Exploratory Study". Watford. Department of the Environment Building Research Section, London.

Bentley, I. (Ed.) (1985). Responsive Environments: A Manual for Designers: The Architectural Press.

Bone, M. (1977). "Pre-School Children and the Need for Day Care". OCPS Social Surgery Division Report, H.M.S.O.

Bullock, N. (2002). Building the Post-War World: Modern Architecture and Reconstruction in Britain. New-York: Routledge.

Burbidge, M. (1981). "Priority Estate Project 1981: Improving Problem Council Estates". London. Housing Development Directorate.

Calthorpe, P. (1993). The Next American Metropolis: Ecology, Community, and the American Dream: Princeton architectural press.

Coleman, A. (1985). Utopia on Trial: Vision and Reality in Planned Housing. London: Hilary Shipman.

Duncan, S. (1988). Public Problems, Private Solutions. London: HM Stationery Office.

Faizi, M., Hosseini, S.-B., \& Asl, S. R. (2008). "Identification of Environmental Design Methods and Techniques for Preventing Vandalism". ENVIRONMENTAL SCIENCES, 6(1), 9-20.

Fanning, D. (1967). "Families in Flats". British Medical Journal, 4, 382-386.

Godfery, P. (1977). Liverpool Learn to Live with Past Housing Mistake. The Times.

Hamid, F., Arar, M., \& Mushtaha, E. (2011). "Urban Form Types and Some Related Social Problems of Multi-Storey Housing in Britain and the Gulf". The Iraqi Journal of Architecture, 22-24.

Hillier, B., \& Shu, S. (2000). "Crime and Urban Layout: The Need for Evidence". In Ballantyne, S., MacLaren, V., \& Pease, K. (Eds.), Secure Foundations: Key Issues in Crime Prevention, Crime Reduction and Community Safety. London: Institute for Public Policy Research.

Mahdjoubi, L. (2007). "Healthy Active Living in Urban Environment". Proceedings of Recent Architectural Development \& Urban Growth in UAE, Ajman University of Science and Technology, UAE.

Medway, J. (1973). Letting the Unlettable. Municipal and Public Services Journal.

Mushtaha, E., \& Hamid, F. (2017). "Review on Vandalism and Mathematical Models for Visibility and Accessibility in Housing Districts, Sharjah City as a Case Study". Open House International, 42(2).

Newman, O. (1973). Defensible Space: Architectural Press.

Ward, C. (1983). Housing: An Anarchist Approach. London: Freedom Press.

Williams, B. T. (1991). "Health Effects of Living in High-Rise Flats". International Journal of Environmental Health Research, 1(3), 123-131.

Wilson, S. (1977). "Vandalism and Design". Architects Journal, 166(43), 795-798. 